\title{
Management Models and Evaluation of Reputation Risks
}

\author{
Oleg M. ZAGURSKIY, Petro I. YUKHYMENKO, Tetyana V. SOKOLSKA, Igor M. PASKA, \\ Viktoria I. LOBUNETS, Tatyana P. ZHYTNYK, Olena B. ZHARIKOVA
}

\begin{abstract}
The article justifies the necessity to develop an analytical basis, management models and assessment of reputational risks. The complexity of the analysis of this category of risks associated with the presence of parameters that differentiate reputational risk from a number of other risks.

The effective management of reputational risk requires constant increase of transparency in reporting, which helps to strengthen the trust of stakeholders by providing reliable, timely and representative information about business. The reputational risks can be identified by two main corporate reporting functions: first, it corrects the expectations of stakeholders, showing how accurate the previous estimates were provided, for the second allows managing further information expectations.

Modeling the level of reputational risk and the magnitude of losses after risk event is an effective tool for taking management decisions by risk management units. Existing methods for the analysis do not take into account the whole range of factors and do not allow to comprehensively assess the consequences of reducing / losing business reputation of banking institutions.

The paper proposes a comprehensive methodology for assessment the level of reputational risks and the size of losses of banking institutions, that allows to combine an expert assessments and a statistical information about incurred losses (loss values), and also proposes the modeling of cause-effect relationships. This model based on the Bayesian belief network and Theory of Fuzzy Sets.

The advantage of such approach is on the possibility to evaluate the probability of some risk events based on the Bayesian theorem, that is, only on expert knowledge, and others based on empirical data on losses, if their volume sufficient for modeling purposes.
\end{abstract}

Key words: business reputation, expert evaluation, information, reputational risk, stakeholders.

\section{INTRODUCTION}

Loss of business reputation may negatively effect on the index of bank activities, result in client's outflow, cut the invested assets reduce banks liquidity and profit and decrease the cost-effectiveness of the banking business.

Revised Manuscript Received on December 22, 2018

* Correspondence Author

Oleg M. ZAGURSKIY, National University of Life and Environmental Sciences of Ukraine, Kyiv, Ukraine

Petro I. YUKHYMENKO, Bila Tserkva National Agrarian University, Bila Tserkva, Ukraine

Tetyana V. SOKOLSKA, Bila Tserkva National Agrarian University, Bila Tserkva, Ukraine

Igor M. PASKA, Bila Tserkva National Agrarian University, Bila Tserkva, Ukraine

Viktoria I. LOBUNETS, Bila Tserkva National Agrarian University, Bila Tserkva, Ukraine

Tatyana P. ZHYTNYK, Bila Tserkva National Agrarian University, Bila Tserkva, Ukraine

Olena B. ZHARIKOVA, National University of Life and Environmental Sciences of Ukraine, Kyiv, Ukraine
Market analysis of the banking services and its main trends is an important stage for identifying reputational threats, as well as factors and reasons of their respective risks, while the modeling of the losses size and risk level itself is an effective tool in developing management decisions by risk management units.

Existing methods of risks analysis do not take into account the whole range of factors and do not allow comprehensively assess the consequences of reducing / losing business reputation of banking institutions. Therefore, the importance in modern conditions takes the development of methodological approaches to assess the reputational risks of banking institutions, methods and tools for managing them.

G. Dowling [2], C. Fombrun [4] and G. Honey [6] made a significant contribution to define the reputational risk of the company, to justify the origin of this risk by non-compliance with the expectations of stakeholders. The influence of business reputation on share value was investigated by K. Jackson [8], J. Klewes and R. Wreschniok [10].

Further researches on improvement the management of the reputational risk system of banking institutions focused on justifying the theoretical foundations and practical recommendations for their implementation in modern conditions. And despite the fact that reputational risks are not regulated by the principles of Basel II and III, their management oriented on strengthening the image and reputation of banks in the eyes of clients and counterparties, increasing their confidence and loyalty, expanding their client base, assuring clients that they will do business with them.

In the presented article, proposed the complex methodology for analysis of the reputational risks level as well as the losses size of banking institutions based on a combination of expert assessments and statistical information on reputational losses, using causal models of Bayesian belief network and the theory of fuzzy sets.

\section{PROBLEMS OF ANALYSIS AND EVALUATION OF REPUTATIONAL RISKS}

Reputation management is a cross-disciplinary system lays between marketing, sociology, public relations, theories of motivation and management, social engineering and a number of other disciplines. It is oriented on company's reaction on factors, which influence its reputation and on solving of complex problems that arise under the influence of a combination of different directions of the company's activities on its public individuality. In such a system, practically none of the managerial decisions is taken in isolation, because all of them

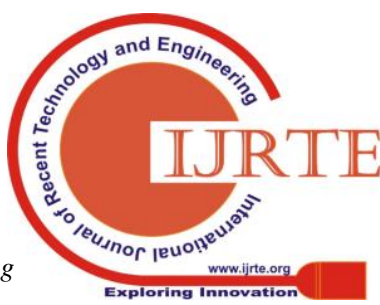


must pass a kind of "filter" to account the reputational risks.

According to G.E. Lemke the reputation as a sociocultural phenomenon by nature is close to myth, which exists to regulate people's behavior in the absence of objective information regarding possible benefits and losses, or in conditions where they do not feel sufficiently competent to assess the available them information. [11]. Positive reputation makes it possible to turn intangible assets into material (in excessive profit), and the negative - brings losses.

At the same time note, that reputation can bring excessive profit, but does not guarantee it, f.e. the economic conditions, crises and other external factors. In addition, as noted by J.-P. Baudouin, the reputation possesses an effect of "memory": any discrepancy between the commitments and behavior of the company, between its communication and real actions will be introduced in the "notepad memory" and absorbs the reputation value of the company incorporated in previous times [1, p 57].

Nowadays internet development conditions, this statement becomes even more relevant, since virtually any information, having hit the Internet, remains there forever, accumulated and analyzed. The total amount of negative information on the Internet over time can gain a "critical mass" and becomes an additional risk factor - the risk of loss of reputation or reputational risk.

1) The essence of reputational risks and the theoretical and methodological principles for improving the scenarios for their analysis are discussed in detail in [16], so let's just focus on the specifics of reputational risks. After all, the complexity of the analysis and evaluation of this category of risks is associated with the presence of parameters that distinguish reputational risk from a number of other risks, namely:

variety of sources of origin. Reputational risk can arise in relations with different groups of stakeholders clients, suppliers, employees, shareholders and investors, creditors, the public, government bodies, etc.

the property of mutual transition to other types of risks (economic, industrial-technical, social and environmental). There is no unambiguous approach to the nature of the origin of this type of risk and its place in the system of risks. Reputational risk can be considered as a consequence of other types of risks, but in the long run it can also lead to new risks for the company;

consistency of existence. Reputational risk appears from various stakeholders in the company's activities and poses a potential threat at any time, which entails the need for its continuous monitoring. Reputational risk can be maintained at a minimum level, but unlike other types of risks, cannot be reduced to zero;

involvement and interconnection of a large number of participants. Since the reputational risk formed due to relationship between the company and its stakeholders, the stronger this link and the bigger the number of parties involved, the higher the reputation risk of the company;

significant spread rate. Analyzing reputational risk, in addition to considering the probability of occurrence of an event and the possible scale of the threat, it is necessary to take into account the speed of spreading the information;

external nature of risk implementation. In spite the fact that increase of reputational risk is internal for the company, the risk assessment and control area is in the external environment and is related to the assessment of

perceived stakeholder engagement. Risk assessments, based on the analysis of perception, are subjective;

the complexity of the consequences elimination. Since the increase of the reputational loss leads to the loss of the stakeholder's confidence, for elimination the consequences, events what happened, is not sufficient to remove the source of the conflict, it needs to be managed the loyalty of the parties.

All of the above characteristics of reputational risks require the development of an analytical framework and models for its management and evaluation. In addition, the Basel II Agreement "International Convergence in Capital Measurement and Capital Standards" considers the bank's reputation risk as part of the 2nd component - the "supervisory process". It recognizes the difficulty of measuring reputational risk and recommended for the banking institutions to develop management techniques and assess all its aspects [7]. Therefore, it is feasible to develop the tools and models for managing and accessing reputational risks.

\section{BUSINESS REPUTATION MANAGEMENT TOOLS}

It should be noted that at first "reputation management" was related to the field of public relations, but the development of computer technology, the Internet and social media has made the reputation dependent on the results of search information. Of course, sometimes this notion used in a negative context, which applies false reviews, negative feedbacks, or the use of $\mathrm{CEO}^{1}$ techniques to influence on search yield.

For example, in 2007, Berkeley University researchers found that some sellers on eBay, in order to gain an advantage over other vendors, managed their reputation by selling a discount product in exchange for favorable references of their activities [12]. However, in most cases, reputation management is a subject to ethical standards and is positively reflected in response on customer complaints, negotiations with site administrations to remove incorrect information and use feedback to improve company products and services.

Therefore, the main task of the company is to manage its reputation and to reduce the number and pessimisation $^{2}$ of the negative information about company in the searched results. In other words, reputation management is an attempt to bridge the gap between how a company positions itself and how the others see it.

The effectiveness of reputational management depends on how it forces to work various information about the company and its actions to increase information's "weight" in the minds of "needed" target audiences. This information can flow from two sides:

1.From external sources, including stock analytical reports, independent journalistic publications, public statements by politicians, consumer feedback in social networks and other.

2. In the first case, the company's influence on the information content and quality preparation is maximal. In the second case, the company is no longer free in controlling the information published - as a rule, in such cases, for the 
companies remain only reactive measures.

In order to improve management of the reputational risk of the company needed constant increase of the reporting transparency, which helps to strengthen the trust of stakeholders by providing reliable, timely and representative information about a business.

However, numerous studies show that at present times, despite the growing demands for information disclosure, stakeholders still do not assess corporate reporting as a sufficient source of information needs.

The most uncertain for stakeholders remain reporting sections on risks, forecasts and prospects, strategy and social and environmental responsibility reporting. At the same time, most public companies issue a report on GRI standards where the above sections are present in the annual report. The main reason hidden in the unrepresentative nature of such information. Disclosure of additional information helps to increase stakeholder's confidence, if such data logically complete the data of the financial reporting and is consistent with each other. Otherwise, this disclosure will not increase the confidence of users and increase the value of the company.

Thus, the main means of managing the reputational risk of a company is the filling of corporate reporting with timely and representative information. However, market participants, shaping their ideas and expectations about the company's prospects, never confined to information disclosed by the management.

Moreover, without having the full information, they cannot accurately assess whether information about a particular event will enter the market, which does not allow investors fully to base their assessments on corporate reporting.

Therefore, the presence of uncontrolled elements of the information field (opinions of other market participants) increases the need to manage reputational risk, which is achieved by monitoring the change in expectations of such participants. Thus, two main functions of corporate reporting can be determined in relation to reputational risks: it corrects the expectations of stakeholders, showing how accurate the previous estimates were and allows future information expectations to be managed.

The level of inclination of the banking institution to reputation risks can be detected based on the reputation matrix and reputation profile of the bank. This approach involves surveying clients, counteragents, media representatives, minority shareholders, employees of credit organizations with the subsequent math's processing of the survey results.

\section{MODELING THE REPUTATION RISK LEVEL FOR THE BANKING INSTITUTION}

In addition, the management of reputational risks requires the identification of a method and procedure for assessing reputational risk based on the extent to which threats from detected and / or predictable sources of threats are realized.

Taken into account the limited methodology for assessing reputational risks and the need to combine quantitative and qualitative methods, the most appropriate approach is to use them in a complex way, combining expert assessments and statistical information on incurred losses (loss rates), and also provides modeling of causal relationships.

The best way to solve this task is to create the casual model, in particular, the use of Bayesian networks of trust [9; 12].

Bayesian networks are graph models of probabilities and causal relationships between variables in statistical information modeling, combining the empirical frequencies of the appearance of different values of variables, subjective estimates of "expectations" and theoretical ideas about the mathematical probabilities of certain or other consequences of a priori information.

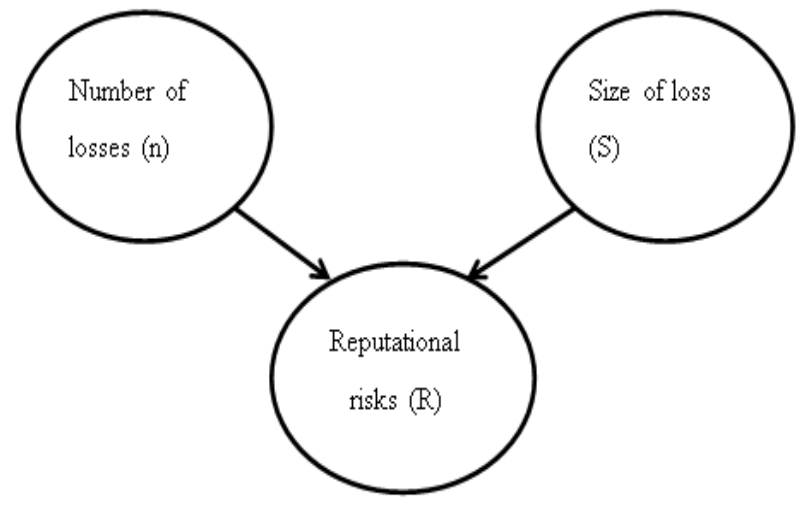

Figure 1. - One-level Bayesian network belief in the assessment of reputational risk

So, in the presented in Fig. 1 network, the probability of staying the vertex $\mathrm{R}$ in different states (Rk) depends on the states (ni, $\mathrm{Sj}$ ) of the vertices $\mathrm{n}$ and $\mathrm{S}$ and is determined by the equation:

$$
p\left(R_{k}\right)=\sum_{i} \sum_{j} p \frac{R_{k}}{n_{i} ; S_{j}} \times p \frac{n_{i}}{S_{j}}
$$

where: $\mathrm{p}(\mathrm{Rk} / \mathrm{ni} ; \mathrm{Sj})$ is the probability of staying in the state Rk depending on the states ni, $\mathrm{Sj}$.

Since events represented by vertices $\mathrm{n}$ and $\mathrm{S}$ are independent, then: (2)

$$
p \frac{R_{k}}{n_{i} ; S_{j}}=p\left(n_{i}\right) \times p\left(S_{j}\right)
$$

In the same time the number of losses will be influenced by the frequency of the impact of reputational threats, which depends on the level of control (the area of reputational risk controlled by the bank) and the power of these threats that are often uncontrollable, while the magnitude of reputational losses - the value of reputational assets and degree their vulnerability (Fig. 2). 


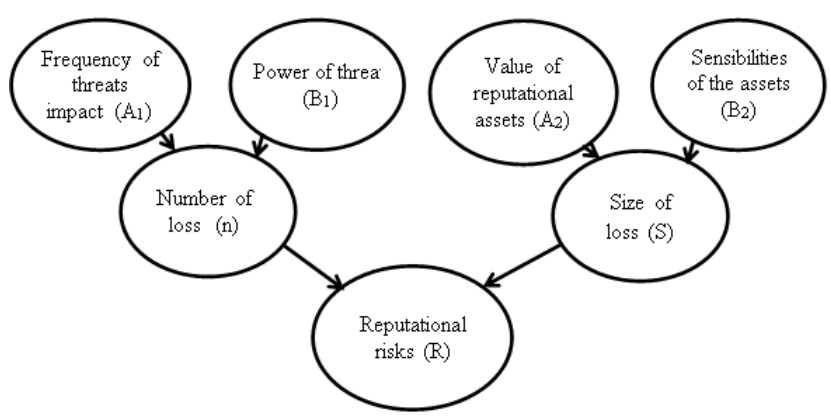

Figure 2. - Two-level Bayesian network belief in the assessment of reputational risk

In this case, the fugure 2 illustrates the conditional independence of the events $\mathrm{n}$ and $\mathrm{S}$. Therefore, for the estimation of vertices $\mathrm{n}$ and $\mathrm{S}$, to be used the same calculations as for calculating $\mathrm{p}(\mathrm{Rk})$, then:

$$
p\left(n_{i}\right)=\sum_{m} \sum_{n} p \frac{n_{i}}{A_{1 m} ; B_{1 n}} \times p\left(A_{1 m}\right) \times p\left(B_{1 n}\right)
$$

$$
p\left(S_{j}\right)=\sum_{m} \sum_{n} p \frac{S_{j}}{A_{2 m} ; B_{2 n}} \times p\left(A_{2 m}\right) \times p\left(B_{2 n}\right)
$$

Also, the vertex $\mathrm{R}$ is conditionally independent of the vertices $\mathrm{A} 1, \mathrm{~A} 2, \mathrm{~B} 1, \mathrm{~B} 2$, since there are no arrows that directly connect these vertices. Thus, the directed acyclic graph has the following parameters:

Each vertex is an event that described by a random variable that can have several states;

- all the vertices associated with the "parent" can be determined using probability tables or conditional probability functions;

- for vertices not related to "parent" probabilities of states are define[5]. variables, and arcs are probabilistic dependencies, which are determined using a table of conditional probabilities. The calculation of the probability of losses from the implementation of reputational risks in the bank can be done using Monte-Carlo simulation of the Microsoft Excel editor.

After constructing a directed graph, to be made an assessment included in it concepts: for the risk events, the probability of their implementation is assessed and, further, the magnitude of the losses associated with them. The probability of implementing events can be specified by Bayesian network belief in the form of a continuous distribution function or in the form of a probability table, that is, in the form of discrete probabilities.

Since continuous distribution functions can only be obtained in rare cases due to insufficient empirical data, it is most advisable to use discrete distributions. For the concepts that have no input arrows on the graph, for example, events that are risk factors, indicate the absolute probability of occurrence of each of the possible results of the event. For those concepts that are influenced by others, the conditional probability for each combination of related concepts is indicated.

V. Improvement of the reputation risk assessment model by introducing a system of relative advantages and preferences
Thefore vertices are represented by random

To improve the constructed model is possible by the theory of fuzzy sets [15]. To do this, the two-level Bayesian network belief constructed by us above (Fig. 2) to be build up a system of relative advantages of $\mathrm{F}$ :

$$
\Phi=\{\mathrm{S} 1\}=\mathrm{n} ; \mathrm{B} 2\}=\mathrm{A} 2 ; \mathrm{B} 1\}=\mathrm{A} 1\} \text { (4) }
$$

in which $"\}=$ " means superiority, and $" \approx$ " indifference.

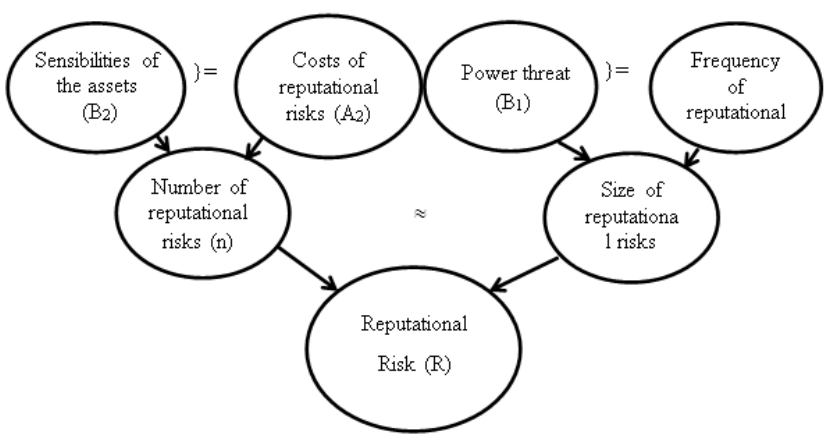

Fig. 3. - The hierarchy $\mathrm{R}$ with the system $\mathrm{F}$ build up on it

In this case, for the assessment of reputational risk quantitatively and qualitatively, to be carried out the aggregation of data, reflected within a defined hierarchy; where the aggregation is carried out in the direction of the arcs of the graph. For the aggregation we use the O'Wa-Jager operator [14], by which the measurement of the degree of aggregation is defined as:

$$
\operatorname{orntss}(W)=\frac{1}{n-1} \sum_{i=1}^{n}(n-i) \times w_{i}
$$

where for any $\mathrm{W}$ orness $(\mathrm{W}) \in[0,1]$, and the weight of the curve is the Fisher's coefficients [3].

$$
\begin{gathered}
\mathrm{p}_{\mathrm{i}}=\frac{2(\mathrm{~N}-\mathrm{i}+1)}{(\mathrm{N}-1) \mathrm{N}} \\
\mathrm{p}_{\mathrm{i}}=\mathrm{N}^{-1}(6)
\end{gathered}
$$

where: $p i$ is the Fisher's weight coefficient for $x i$;

$\mathrm{N}$ - total number of indicators in the hierarchy, $\mathrm{N}>0$;

$\mathrm{i}$ - is the serial number of xi in the group.

In the system indifferent to each other $\mathrm{N}$ alternatives - the set of equal weights is equal to:

$\mathrm{f}$ the system includes only preferences, then:

$\mathrm{N}=1, \mathrm{r}_{\mathrm{i}-1}=\mathrm{r}_{\mathrm{i}}+1, \mathrm{~K}=1+2+\ldots+\mathrm{N}=\mathrm{N}(\mathrm{N}+1) / 2$ (7)

where: ri - numerators of recursive fractions;

$\mathrm{K}$ - the sum of the received numerators or the common denominator of fractions of Fishburne

Therefore:

$$
\mathrm{p}_{\mathrm{i}}=\mathrm{r}_{\mathrm{i}} / \mathrm{K}(8)
$$

In this case, the membership function of the factor-effect deviation value is given by a fuzzy set:

$$
\begin{aligned}
\mu_{[0 ; 1]}\left(X_{s}^{r}\right) & =\left\{X_{s_{1}}^{r} / V_{1}, X_{s_{2}}^{r} / V_{2}, \ldots, X_{s_{n}}^{r} / V_{n}\right\}_{(9)} \\
& \text { where:, } . X_{s_{1}}^{r}, \ldots, X_{s_{n}}^{r}-\text { value of the factor after }
\end{aligned}
$$
enlargement

$\mathrm{V} 1, \ldots, \mathrm{Vn}$ - subjective evaluations of the possibility of corresponding increases in the factor-effect for a given factor-factor increase.

The meaning of some concepts included in the R hierarchy can be quantified, for example, after processing the collected statistical data. However, in most cases, the numerical determination of the factors

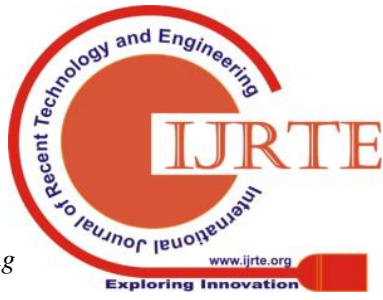


values to be carry out by the expert evaluation methods.

Therefore, to formalize the information received from the expert, it is suggested to introduce a linguistic variable with a term-set of values: $\mathrm{QL}=\{$ Low $(\mathrm{H})$; Below average (NA); Average. (WITH); Above average (Sun); High (B) $\}$.

To proceed to the quantitative description of this term-set, it is expedient to put in correspondence a five-level classifier in which the membership functions $(\mathrm{F})$ of fuzzy numbers given on the segment $[0 ; 1]$, there are trapezes:

$\{\langle\mathrm{H} »(0 ; 0 ; 0,15 ; 0,25) ;\langle\mathrm{HC} »(0,15 ; 0,25 ; 0,35$; $0,45) ;\langle\mathrm{C} »(0,35 ; 0,45 ; 0,55 ; 0,65) ;\langle\mathrm{BC} »(0,55 ; 0,65 ; 0,75$; $0,85) ;$ «B» $(0,75 ; 0,85 ; 1 ; 1)\}$.

Consequently, if for each indicator $(X * 1 \ldots X * N)$ the linguistic estimates are known on the selected subset of the hierarchy, and also a certain system of Fischer's weights is determined on the basis of the system of preferences of $F$, then the linguistic estimates are determined from the relations of the system of membership functions:

$$
\begin{aligned}
& 1 ; 0 \leq x<0,15 \\
& \text { OH: } \mu 1(x)=10(0,25 \\
& 15 \leq x<0,25 \\
& 0 ; 0,25 \leq x<1 \\
& 0 ; 0 \leq x<0,15 \\
& 10(x-0,25) ; 0, \\
& 15 \leq x<0,25 \\
& H: \mu 2(x)=1 ; 0, \\
& 15 \leq x<0,35 \\
& 10(0,45-x) ; 0, \\
& 35 \leq x<0,45 \\
& 0 ; 0,45 \leq x \leq 1 \\
& 0 ; 0 \leq x<0,35 \\
& 10(x-0,35) ; 0, \\
& 35 \leq x<0,45 \\
& C: \mu 3(x)=1 ; 0, \\
& 45 \leq x<0,55
\end{aligned}
$$$$
\mathrm{OH}: \mu 1(\mathrm{x})=10(0,25-\mathrm{x}) ; 0 \text {, }
$$

$$
\begin{aligned}
& 10(0,65-\mathrm{x}) ; 0,55 \leq \mathrm{x}<0,65 \\
& 0 ; 0,65 \leq \mathrm{x} \leq 1 \\
& 0 ; 0 \leq \mathrm{x}<0,55 \\
& 10(\mathrm{x}-0,55) ; 0,55 \leq \mathrm{x}<0,65
\end{aligned}
$$

B: $\mu 4(x)=1 ; 0$,

$65 \leq \mathrm{x}<0,75$

$$
\begin{aligned}
& 10(0,85-x) ; 0 \\
& 75 \leq x<0,85 \\
& 0 ; 0,85 \leq x \leq 1 \\
& 0 ; 0 \leq x<0,75
\end{aligned}
$$$$
\text { OB: } \mu 5(x)=10(x-0,75) \text {; }
$$$$
0,75 \leq \mathrm{x}<0 \text {, }
$$$$
85
$$

$$
0 ; 0,85 \leq \mathrm{x}<1
$$

If, in addition to factors evaluated qualitatively ("unclear"), concepts are present that are quantified ("clearly"), then for the joint use of quantitative and qualitative information, it is advisable to use the method proposed in [7], which involves the calculation of the normalized value of the quantifiable factor for the formula

$$
\bar{F}_{i}=\frac{F_{i}-F_{\min }}{F_{\max }-F_{\min }}
$$

\section{CONCLUSIONS}

Reputation risk management is a process, focused on the object (bank) that is carried out to organize its operation according to the planned program, in light of the reduction and leveling of risks that threaten business reputation. The process of direct impact on the object is preceded by a procedure of assessment the reputational risks through quantitative and qualitative methods. To model the level of reputation risk, has been applied the graph of two-tier Bayesian's network belief model, with the system of advantage relations imposed on it. The sequence of application of the described approach is as follows:

1. The calculation of absolute probabilities of the implementation of a risk case on the basis of the conditional probability formula, which allows them to be determined by comparing the given conditional probabilities and known probabilities of the implementation of risk cases or the causes (factors) of occurrence of risk cases.

2. Calculation of the magnitude of possible losses from the realization of a risk case is made on the basis of statistics, expert way. The amount of direct financial losses can be determined on the basis of professional experience of experts or on the basis of operating losses. Losses can also be estimated in probabilistic terms, using confidence intervals or distributions.

3. The construction of a graph model of a two-tier Bayesian network belief with an override system imposed on it, as well as aggregation of data using the OWA-Jager operator using Fischer's coefficients with ordered weights, can reveal the degree of reputation risk and the level of losses of investigated banks.

4. The advantage of such an approach is the possibility of evaluating the probability of some risk events based on the Bayesian theorem, that is, only on expert knowledge, and others on the basis of empirical data on losses, if their volume is sufficient for modeling purposes. Sources of threats, possible risk events, form the basic part of the concepts of the Bayesian network. Violator models supplement them. In addition, the model should include events that could be the consequences of the implementation of risk in the assets of the bank.

In the course of these events, the bank suffers the main losses, as the greatest damage to the bank is caused not by risk factors it selves, but by the associated stop or violation of business processes important for the bank's mission.

\section{REFERENCES}

1. Beaudoin J.-P., L’opinion, c’est combein? Pour une économie de l'opinion Paris, Village Mondial, 2005.

2. Dowling G. Creating Corporate Reputations: Identity, Image, and Performance Oxford University Press, USA, 2002.

3. Fishburn P. Utility Theory Management Science, 1968, Vol. 14, No. 5. 335-378.

4. Fombrun C.J. Reputation: Realizing Value from the Corporate Image Harvard Business School Press, 1996.

5. Heckerman D. A Tutorial on Learning with Bayesian Networks. In Learning in Graphical Models, M. Jordan, ed 
MIT Press, Cambridge, MA, 1999.

6. Honey G. A short guide to reputation risk Gower Publishing Ltd., 2009.

7. International Convergence of Capital Measurement and Capital Standards Basel Committee on Banking Supervision. 2006 URL: https://www.bis.org/publ/bcbs128.pdf.

8. Jackson K.T. Building Reputational Capital: Strategies for Integrity and Fair Play that Improve the Bottom Line Oxford University Press, 2004.

9. Jensen, F.V. Bayesian Networks and Decision Graphs NY: SpringerVerlag, 2001.

10. Klewes J., Wreschniok R. Reputation Capital: Building and Maintaining Springer, 2009.

11. Lemke G.Je. Sekrety kommercheskoj razvedki Moskva.: Os'-89, 2008.

12. Mills E., Study: eBay sellers gaming the reputation system? [Electronic resource]. $\quad-\quad$ Access mode: http://news.cnet.com/8301-10784_3-6149491-7.html.

13. Pearl, J. Probabilistic Reasoning in Expert Systems: Networks of Plausible Inference San Francisco: Morgan Kaufmann, 1988.

14. Yager, R. Families of OWA Operators Fuzzy Sets and Systems, 59, 1993. 125-148.

15. Zadeh L. Toward a theory of fuzzy information granulation and its centrality in human reasoning and fuzzy logic. Fuzzy sets and systems, 1997. Vol. 90, No. 2. 111-127.

16. Zagurskiy $\mathrm{O}$. The essence of reputation risks and their management in the banking sector Financial and credit activity: problems of theory and practice 2017. T 2. Vol. 23. 38-44. 